\title{
Transcription conventions
}

CU close-up

MCU mid close-up

MLS mid long shot

LS long shot

$\mathrm{v} / \mathrm{o} \quad$ voice over

[ Links simultaneous speech

: $\quad$ vowel lengthening

(.) pause

$\mathrm{xx}^{-} \quad$ incomplete utterance

$=\quad$ latching (immediate follow-on)

(xx) indistinct utterance

.h inhalation

$\mathrm{h}$ exhalation

(h) laughter in speech

? rising intonation

$>$ relative increase in rate of delivery shown by number of chevrons $<$ $<$ relative decrease in rate of delivery shown by number of chevrons $>$ heavy emphasis

LOUDNESS

[gestures and other 'business'] 
